\title{
Economic Comparison of Power and Chilled Water Generation by Cogeneration System and Public Utility
}

\author{
Adzuieen Nordin ${ }^{1}$ and Mohd Amin Abd Majid ${ }^{2}$ \\ ${ }^{1,2}$ Faculty of Mechanical Engineering, Universiti Teknologi PETRONAS
}

\begin{abstract}
The paper presents an economic comparative study on the electricity and chilled water generation between using cogeneration system and public utility. A comparative evaluation using Net Present Value method was adopted in this study. The study shows that using cogeneration system is economically feasible compared to PU if the failure frequency per year is 5 or less.
\end{abstract}

\section{Introduction}

In general, public utility (PU) provides electricity requirements for the domestic and industrial consumers. In some cases, power could also be independently generated by consumers or industries using decentralized power plants. Some of these plants could also produce chilled water through cogeneration systems. In cogeneration system, the electricity is generated by Gas Turbine (GT) and the waste heat from the plant is used to produce steam by Heat Recovery Steam Generator (HRSG). The steam is then used for production of chilled water using Steam Absorption Chiller (SAC). The utilization of the waste heat from the turbines contribute the reduction of the energy costs as reported by Donghao Xu and Min Qu [1]. Economic study on the system had been undertaken. One such study is by Omar F. Can et al. [2], it is indicate that the payback period of cogeneration plant is 3.65 years. This proves that the cogeneration plant is profitable. It is also reported that the efficiency of the system is between $80-90 \%$ which is considered the system is efficient. Other studies have also addressed the benefits of cogeneration system [3], [4], [5] and [6]. Among the benefits are by using the cogeneration system, the amount of fuel used is reduced and reduced environment emission. However, one of the disadvantages, the plant requires a PU back up when the turbines failed. The study of using electricity from PU as a back-up was done by Alexis and Liakos [7]. This is to overcome the electricity deficit for the cogeneration system in a hospital in Greece. The used of back up from the PU will increase the cost of operation of the cogeneration system. This study is looking into comparison between the operational cost of cogeneration plant and using PU for the electricity and chilled water generation.

\section{Methodology}

Net Present Value (NPV) approach is used for this study. The approach requires the acquisition of relevant cost data. The data needs to be analysed. The steps involved are; 
Estimated the operation cost of the cogeneration system. The process flow of the power and chilled water generation are shown in Figure 1a.

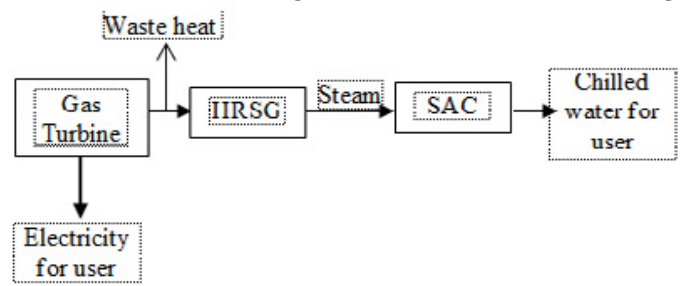

Figure 1a. Schematic diagram of cogeneration system.

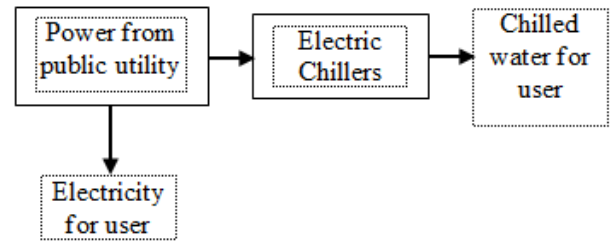

Figure 1b. Schematic diagram of distribution power by PU.

The operating cost of the cogeneration system consists of annual cost of fuel $\left(C_{f}\right)$, capital recovery of equipment $\left(C_{R}\right)$, annual cost of operation and maintenance $\left(C_{\text {O\&M }}\right)$, maximum demand charged per year $\left(C_{D}\right)$ and annual electricity cost when the GT failed $\left(C_{E}\right)$. The maximum demand charged is imposed when the plant has to be hooked up to the PU for power supply when GT failed.

The total annual operation cost of using cogeneration system was calculated as Eq. (1).

$$
\text { Total annual operation cost }=\left(C_{f}\right)+\left(C_{R}\right)+\left(C_{\text {O\&M }}\right)+\left(C_{D}\right)+\left(C_{E}\right)
$$

where;

\section{$C_{f}=\dot{m}_{f} \times L H V \times \sum_{i=1}^{n} G T_{i} \times$ no. of hours running $\times$ no. of days running per year $\times R_{C F}$}

where $\dot{m}_{f}$ is the mass flow rate of the fuel $(\mathrm{kg} / \mathrm{s}), L H V$ is a Low Heating Value of the fuel, $i$ is a number of GT running and $R_{C F}$ is the cost of fuel per unit of energy (RM/kWh).

$C_{R}=\sum_{n} \sum_{m} C_{n m}(A / P, i \%, N)-S_{l(n m)}(A / P, i \%, N)$

where $C_{R}$ is the capital cost of the equipment (RM), $n$ is the equipment type, $m$ is the equipment number, $S$ is the salvage value of the $J$ equipment $(\mathrm{RM})$ and $(A / P, i \%, N)$ is the capital recovery factor.

$C_{\text {o\&M }}=C_{\text {operation }(j)}+C_{\text {repair }(j)}+C_{\text {maintenance }(j)}$

where, $j$ is a type of equipment, $C_{\text {operation }(j)}$ is a labor cost, $C_{\text {repair }}$ refers to the cost of repairing damage and $C_{\text {maintenance }}$ is refer to routine maintenance yearly.

$C_{D}=$ Maximum demand charged by public utility $\times \sum_{i=1}^{n} F_{f}$

where $F_{f}$ are a number of failures.

\section{$C_{E}=$ Capacity of $G T \times e_{R} \times$ no. of hours electricity supply from $P U \times \sum_{i=1}^{n} F_{i}$}

where $e_{R}$ is the electricity tariff rate and $F_{i}$ is a number of failures.

(ii) Estimated the operation cost using Electric Chiller (EC) with power supply from PU. The total power for operation of EC was assumed to be supplied by the PU while the chilled water demand was fulfilled through the electric chillers. The schematic diagram of the distribution of power by a PU is shown in Figure $1 \mathrm{~b}$. 
In order to estimate the annual operation cost using EC with electrical supply from PU, the method used is divided into five steps;

(i) Identifying the amount of electricity for the user. This was obtained from historical data from the plant.

(ii) Estimation the amount of chilled water generated. The number of EC needed was based on the estimation of chilled water generated daily. The estimation of the chilled water was based from the historical data.

(iii) Identifying the number of EC required was calculated using Eq. (7).

No. of EC $=(x /$ no.of hours operation $) /$ Capacity of $E C$

where $x$ is the amount of chilled water generated.

(iv) Estimation of total annual electricity consumption calculated using Eq. (8).

Total annual electricity consumption for $y E C$

$=$ power rating of $E C \times y \times$ no. of hours running

where $y$ is the number of EC.

(v) Estimation of total annual costs of using EC was calculated using Eq. (9).

Total annual cost of using EC

= Capital Recovery of installation PU substation

+ Capital Recovery of EC + Annual costs of electricity supply to user

+ Annual cost of electricity consumption using y ECs

where the capital recovery of installation PU substation is defined in Eq. (10).

$C_{R(\text { substation })}=C_{\text {(substation) }}(A / P, i \%, N)$

where $C_{\text {(substation) }}$ is the capital cost of installation the PU substation (RM) and $(A / P, i \%, N)$ is a capital recovery factor. While, the capital recovery of EC was calculated by Eq. (11).

$C_{R(E C)}=\sum_{l=1}^{n} C_{l(E C)}(A / P, i \%, N)-S_{l(E C)}(A / P, i \%, N)$

where $C_{I(E C)}$ is the capital cost of EC (RM) which is $I$ is the number of EC, $S_{I}$ is the salvage value of $\mathrm{EC}(\mathrm{RM})$.

The annual cost of electricity consumption for $y$ ECs to generate chilled water was calculated by Eq. (12).

Annual costs of electricity consumption by $y E C s=$ (Power rating of EC $\times y \times$ no. of hours running $\times$ no. of days $\times e_{R}$ )

The annual cost for electricity supply to the user is shown in Eq. (13).

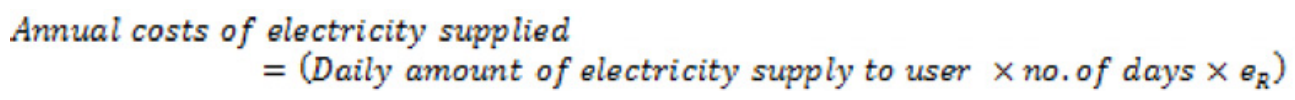

\section{Case Study}

UTP GDC plant was selected for the case study. The plant generated power and chilled water. The plant operating parameters are shown in Table 1. 
Table 1. Operating parameters for UTP GDC plant

\begin{tabular}{lll}
\hline Equipment & Operating conditions & Value \\
\hline GT & $\dot{m}_{f}$ & $0.26 \mathrm{~kg} / \mathrm{s}$ \\
& LHV & $41000 \mathrm{~kJ} / \mathrm{kg} . \mathrm{K}$ \\
& Capacity per unit & $4.2 \mathrm{MW}$ \\
HRSG & Capacity per unit & $12 \mathrm{ton} / \mathrm{hr}$ \\
SAC & Capacity per unit & $1250 \mathrm{RT}$ \\
EC & Capacity per unit & $325 \mathrm{RT}$ \\
& Electricity consumption per unit & $300 \mathrm{kWh}$ \\
TES & Capacity per unit & $10000 \mathrm{RTh}$ \\
\hline
\end{tabular}

Table 2. UTP GDC economic parameters

\begin{tabular}{|c|c|c|c|c|c|c|}
\hline & Units & GT & HRSG & SAC & EC & $\begin{array}{c}\text { TNB } \\
\text { substation }\end{array}$ \\
\hline No. of units & (units) & 2 & 2 & 2 & 4 & 1 \\
\hline $\begin{array}{l}\text { Operating hours per } \\
\text { unit }\end{array}$ & (hrs) & 20 & 12 & 12 & 12 & - \\
\hline $\begin{array}{l}\text { Operating days per } \\
\text { unit }\end{array}$ & (days) & 365 & 365 & 365 & 365 & - \\
\hline Cost of fuel & $(\mathrm{RM})$ & $14 / \mathrm{GJ}$ & - & - & - & - \\
\hline $\begin{array}{l}\text { Estimated price per } \\
\text { unit rate }\end{array}$ & (RM) & $\begin{array}{l}1.5 \mathrm{M} / \\
\mathrm{MW}\end{array}$ & $\begin{array}{c}0.4 \mathrm{M} / \text { ton } \\
\text { steam }\end{array}$ & $4000 / \mathrm{RT}$ & $550 / \mathrm{RT}$ & - \\
\hline $\begin{array}{l}\text { Salvage value of the } \\
\text { equipment }\end{array}$ & $(\mathrm{RM})$ & \multicolumn{4}{|c|}{ Assumed $10 \%$ of the capital recovery cost } & - \\
\hline $\begin{array}{l}\text { Cost of Operation \& } \\
\text { Maintenance }\end{array}$ & $(\mathrm{RM})$ & \multicolumn{4}{|c|}{$3.8 \mathrm{M} /$ year } & - \\
\hline $\begin{array}{l}\text { Maximum demand } \\
\text { charged }\end{array}$ & $(\mathrm{RM})$ & - & - & - & - & $\begin{array}{c}56.80 / \mathrm{kW} \\
{[8]} \\
\end{array}$ \\
\hline Electricity tariff rate & (RM) & - & - & - & - & $\begin{array}{c}0.29 / \mathrm{kWh} \\
{[8]}\end{array}$ \\
\hline $\begin{array}{l}\text { Annual Capital } \\
\text { recovery of } \\
\text { installation }\end{array}$ & $(\mathrm{RM})$ & - & - & - & - & $9 \mathrm{M}$ \\
\hline
\end{tabular}

\section{Results and discussion}

(i) Electricity generation.

The data on electricity production was based on the plant operating data. Figure 2 shows the hourly electricity generation from $6^{\text {th }}$ May 2013 to $10^{\text {th }}$ May 2013 in the UTP GDC plant.

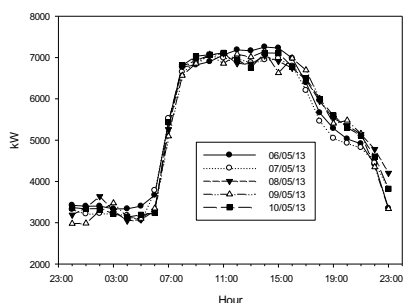

Figure 2. Hourly electricity generation by UTP GDC plant.

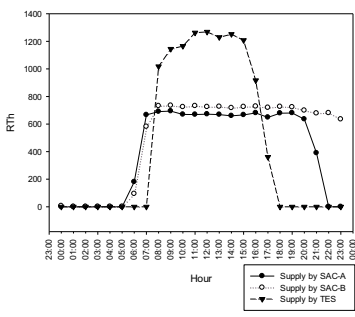

Figure 3. Hourly chilled water generation by UTP GDC plant. 
Figure 2 shows that the trend of the electricity generation is almost similar for five working days. The electricity generated was higher during peak period 7.00 a.m. to 7.00 p.m. During this period, both GT were operated in order to fulfill the electricity requirements. While during off peak period, only one GT was operated. The daily average amount of electricity generated was around 127000 kWh.

(ii) Chilled water generation.

Based on the historical data, the plot of chilled water generated is shown in Figure 3. The chilled water was supplied from two SACs and one TES during peak hour. The total daily chilled water generated by the SACs and TES was about 32E3 RTh.

The operation cost of using cogeneration system

Estimation of operation cost using cogeneration plant was calculated using Eq. (1). The results are shown in Table 3.

Table 3. Estimated annual operation cost of cogeneration plant.

\begin{tabular}{lccccccccc}
\hline \hline & $C_{f}$ & $C_{R}$ & $C_{\text {O\&M }}$ & $C_{D}$ & $\begin{array}{c}C_{\bar{E}} \\
(f=1)\end{array}$ & $\begin{array}{c}C_{\bar{E}} \\
(f=2)\end{array}$ & $\begin{array}{c}C_{\bar{E}} \\
(f=3)\end{array}$ & $\begin{array}{c}C_{\bar{E}} \\
(f=4)\end{array}$ & $\begin{array}{c}C_{\bar{E}} \\
(f=5)\end{array}$ \\
\hline \hline $\begin{array}{l}\text { Annual } \\
\begin{array}{l}\text { cost } \\
\text { RM }\end{array}\end{array}$ & 7.8 & 3.41 & 3.8 & 0.4 & 0.05 & 1.05 & 1.58 & 2.10 & 2.63 \\
Million) & & & & & & & & & \\
\hline
\end{tabular}

From Table 3, it is noted the total annual cost of using cogeneration for electricity and chilled water production depends on number of failure. The annual cost increased while the increase of the number of failure. The estimated cost was based on $i=10 \%$, plant life of 20 years.

The annual operation cost based on EC using electrical supply from PU

Eq. (7) was used to estimate the number of EC required to fulfill the chilled water requirements daily. From Figure 4, it is estimated that 32872 Rth is required daily. The results shown, nine (9) ECs were needed to generate chilled water demand. The capital cost of EC was calculated by Eq. (11) and the estimated results is RM0.17 Million. Assuming the electricity consumption for one EC is 300 $\mathrm{kWh}$, the total costs of electricity consumption for nine ECs were calculated by using Eq. (12). It is estimated that the total cost of using nine ECs is RM3.5 Million. Eq. (13) was used to estimate the total cost of electricity charged by the PU to fulfill the electricity demand. Summary of the results is shown in Table 4.

Table 4. Summary of operation cost based on PU tariff.

\begin{tabular}{ll}
\hline Costs & RM \\
\hline \hline Cost of TNB substation installation & $1.01 \mathrm{M}$ \\
\hline Cost of electricity consumption for nine ECs & $3.5 \mathrm{M}$ \\
\hline Capital Recovery cost of EC & $0.17 \mathrm{M}$ \\
\hline Cost of electricity charged by PU & $13.4 \mathrm{M}$ \\
\hline \hline Total cost & $18.08 \mathrm{M}$ \\
\hline \hline
\end{tabular}

\section{Break-even analysis}

From the comparison, the results shown that the estimated operation costs of power and chilled water using cogeneration plant is lower than using PU. The operation costs using cogeneration plant increased when the number of failures increased as shown in Figure 4. From the break even analysis, PU proves to be better option if the failure of the GT is more than 5 times. 


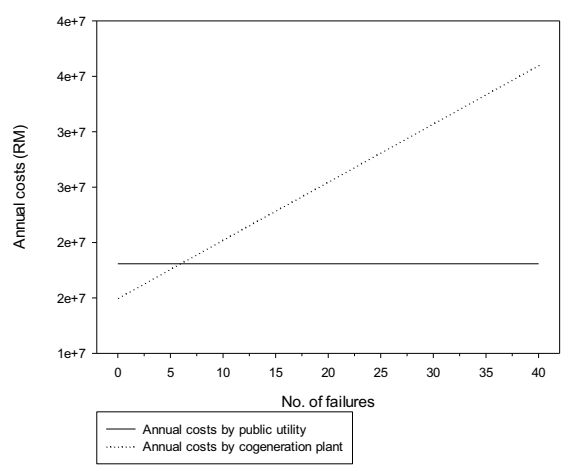

Figure 4. Break even analysis diagram.

\section{Conclusions}

GDC plant in UTP produced electric power and chilled water for the campus requirements. The comparative study of the economic feasibility was done in order to identify the profitable method to produce electricity and chilled water. The NPV approach was used for two cases namely cogeneration system and PU. The results indicate, the annual operation cost of using cogeneration plant is lower than using PU. However, from the break even analysis for both cases, if the GT failures frequencies are more than 5 times per year, PU option is more economic.

\section{References}

1. $\mathrm{Xu}, \mathrm{D}$. and M. Qu, Energy, environmental, and economic evaluation of a CCHP system for a data center based on operational data. Energy and Buildings, 67: p. 176-186 (2013).

2. Can, O.F., N. Celik, and I. Dagtekin, Energetic-exergetic-economic analyses of a cogeneration thermic power plant in Turkey. International Communications in Heat and Mass Transfer, 36(10): p. 1044-1049 (2009).

3. Kanoglu, M. and I. Dincer, Performance assessment of cogeneration plants. Energy Conversion and Management, 50(1): p. 76-81 (2009).

4. Khaliq, A. and S.C. Kaushik, Thermodynamic performance evaluation of combustion gas turbine cogeneration system with reheat. Applied Thermal Engineering, 24(13): p. 17851795 (2004).

5. El-Halwagi, M., D. Harell, and H. Dennis Spriggs, Targeting cogeneration and waste utilization through process integration. Applied Energy, 86(6): p. 880-887 (2009).

6. Armanasco, F., et al., Techno-economic evaluation of commercial cogeneration plants for small and medium size companies in the Italian industrial and service sector. Applied Thermal Engineering, 48: p. $402-413$ (2014).

7. Alexis, G.K. and P. Liakos, A case study of a cogeneration system for a hospital in Greece. Economic and environmental impacts. Applied Thermal Engineering, 54(2): p. 488-496 (2013).

8. Suhala S., Customised Contract Hume, Cogen UTP, TIK General-Medium Voltage Peak/Off Peak Commercial Bulk Supply Tariff, email from Suhala Sukarno to Azanin Bismi A., Cheah P.W, 15 January (2014). 